\title{
Gender Differences in Aesthetic Rhinoplasty Patients: A Study on Psychopathological Symptoms
}

\author{
Mohsen Naraghi ${ }^{1,2,3}$, Mohammad Atari ${ }^{*}$ \\ ${ }^{1}$ Division of Rhinology and Facial Plastic Surgery, Department of Otorhinolaryngology, Head and Neck Surgery, \\ Tehran University of Medical Sciences, Tehran, Iran \\ ${ }^{2}$ Otorhinolaryngology Research Center, Tehran University of Medical Sciences, Tehran, Iran \\ ${ }^{3}$ Rhinology Research Society, Tehran, Iran \\ ${ }^{4}$ Department of Psychology, University of Tehran, Tehran, Iran \\ Email: info@naraghi.ir, “Atari@ut.ac.ir
}

Received 3 November 2015; accepted 4 January 2016; published 7 January 2016

Copyright (C) 2016 by authors and Scientific Research Publishing Inc.

This work is licensed under the Creative Commons Attribution International License (CC BY).

http://creativecommons.org/licenses/by/4.0/

(c) (i) Open Access

\begin{abstract}
The aim of the current study was to investigate the gender differences in aesthetic rhinoplasty candidates in dimensions of psychopathology. Considering the existing body of literature, it was hypothesized that women would score higher in different dimensions of psychopathology. SCL-90-R was used to evaluate the differences. This instrument consists of 10 subscales which measure depression, anxiety, phobia, hostility, obsessive-compulsive symptoms, interpersonal sensitivity, somatization, paranoid ideation, psychoticism, and added items of psychopathology. Independent $t$-test between male patients $(n=19)$ and female patients $(n=32)$ was performed. Findings indicated that women had higher scores in four subscales. Women had higher scores in anxiety $(P<0.01)$, obsessive-compulsive symptoms $(P<0.05)$, depression $(P<0.05)$, and added items $(P<0.05)$. Effect size measures were calculated in order for better interpretation of statistical significance tests. Findings supported the notion that women who applied for aesthetic rhinoplasty showed higher scores of anxiety, depression, obsessive-compulsive symptoms, and general psychopathological symptoms. Surgeons can utilize validated psychometric instruments in order to screen psychologically disturbed patients as these patients are more likely to show dissatisfaction after the surgery.
\end{abstract}

\section{Keywords}

Aesthetic Surgery, Gender, Psychopathology, Rhinoplasty

\footnotetext{
${ }^{*}$ Corresponding author.
}

How to cite this paper: Naraghi, M. and Atari, M. (2016) Gender Differences in Aesthetic Rhinoplasty Patients: A Study on Psychopathological Symptoms. Open Journal of Medical Psychology, 5, 1-6. 


\section{Introduction}

Cosmetic surgery has gained increasing attention in the past few decades [1]. Psychological implications of cosmetic surgery are of no doubt as studying various aspects of these operations may bring to light more facts about the underlying psychology of cosmetic plastic surgery. This fact seems more important considering the increase in desire for this type of elective surgery over the past decade.

It has been suggested [2] that cosmetic surgery is essentially body image surgery and that physical modifications will therefore enhance body image perceptions and self-esteem [3]. However, the evidence to support such a direct and causal relationship is mixed, at best. A review of the evidence [4] concluded that it was scientifically premature to assume that cosmetic surgery necessarily led to direct psychological benefits. There appears a general lack of well controlled research into the range of possible psychological outcomes following cosmetic surgery.

Psychologically, the face has a crucial symbolic role in one's appearance. The obsession with facial beauty is not new in the history. There is cross-cultural evidence [5] suggesting that perception of facial attractiveness is relatively independent of culture. Generally, attractive faces activate reward centers in the brain [6], they motivate sexual behavior and development of same-sex alliances [7], and they elicit positive treatment in various settings [8]. Therefore, having an attractive face may improve social, psychological, and sexual quality of life. Historically, the face has been considered the personification of one's soul. From the social point of view, it is the representation of the person's identity [9]. All facial parts are of absolute importance for perception of facial beauty; however, the nose has a particular role. Nose is also the most prominent anatomic part of the face. The nose's role is critical not only for the anatomy of the face, but also because this organ is one of the factors that can disturb one's body image more than other facial components [10]. Thus, aesthetic rhinoplasty has become one of the most commonly requested cosmetic procedures around the world.

Psychopathological research suggests that aesthetic rhinoplasty volunteers exhibit stronger psychopathological symptoms [11] [12]. Findings indicate that patients seeking aesthetic rhinoplasty fare worse in somatization, anxiety, depression [13], social dysfunction, depression, general health [14], and self-esteem [15] [16]. Moreover, interest in aesthetic rhinoplasty is associated with lowered body appreciation [17] and high levels of appearance-related social comparisons [18]. Body Dysmorphic Disorder (BDD) has also been associated with interest in rhinoplasty [19]. Furthermore, BDD may be presented with depression or other psychiatric disorders. Therefore, preoperative assessment could be of great help to define the clinical profile of patients in cosmetic surgery settings.

In this respect, gender differences have not been primarily focused on. Women are generally more interested in cosmetic procedures and will consider them more frequently in comparison with men [20]. Furthermore, it has been reported that women obtain lower scores in general body appreciation [21] as a measure of positive body image. The available evidence also suggests that women report a greater possibility of willingness to undergo different cosmetic procedures in comparison with men [22], which has been explained as a function of the greater sociocultural pressure on women to attain ideals of physical attractiveness. This study aimed to explore potential gender differences in psychopathology of rhinoplasty.

\section{Method}

\subsection{Participants}

Participants of this study were 51 patients who were scheduled to undergo aesthetic rhinoplasty. The sample consisted of 19 men and 32 women who were selected consecutively. Participants' age ranged from 17 to 59 (M = 26.9, SD $=8.8$. Twenty nine patients were single $(56.9 \%), 20$ were married $(39.2 \%)$ and 2 were separated (3.9\%). Demographic characteristics of both groups are presented in Table 1.

\subsection{Measures}

\subsubsection{Symptom Check List-90-Revised}

Participants completed the revised form of SCL-90 preoperatively. SCL-90-R is a widely used self-report instrument to assess the psychopathological symptoms of an individual [23]. It consists of 90 items defined in 9 symptom dimensions (depression, anxiety, phobia, hostility, obsessive-compulsive disorder, interpersonal sensitivity, somatization, paranoid ideation, and psychoticism). There is also one subscale with 7 items which measures 
Table1. Demographic characteristics of patients.

\begin{tabular}{ccc}
\hline Variable & Male patients $(\mathrm{n}=19)$ & Female patients $(\mathrm{n}=32)$ \\
\hline Age (SD) & $25.74(6.91)$ & $27.63(9.79)$ \\
Marital status & & \\
Single & $15(79 \%)$ & $14(44 \%)$ \\
Married & $4(21 \%)$ & $16(50 \%)$ \\
Separated & $0(0 \%)$ & $2(6 \%)$ \\
Educational level & & \\
High school or lower & $5(26 \%)$ & $10(31 \%)$ \\
Bachelor's degree & $10(53 \%)$ & $19(59 \%)$ \\
Master's degree or higher & $4(21 \%)$ & $3(10 \%)$ \\
\hline
\end{tabular}

general psychopathological symptoms and is used in calculating different indices of SCL-90-R. The higher scores correspond to stronger severity of symptoms. The 90 items in the questionnaire are scored on a five-point Likert scale, indicating the rate of occurrence of the symptom during the time reference. Cronbach's alphas of the subscales in this study ranged between 0.65 (psychoticism) and 0.87 (depression).

\subsubsection{Demographics}

Participants also provided their demographic details consisting of gender, age, marital status, and educational level.

\subsection{Procedure}

Permission for ethics purposes was obtained from university's ethics committee. Participants were recruited using convenience sampling method in a consecutive manner. Respondents provided informed consent and were debriefed about the objectives of the study only after they had finished filling the questionnaires. All data were treated confidentially and questionnaires were preserved in a safe place. All completed questionnaires were included in the study as no one had left more than $10 \%$ of the responses blank.

\subsection{Statistical Analyses}

Statistical data analyses were performed in a blinded fashion. Data analysts were not involved in the process of data collection. In order for examining the gender differences in psychopathological symptoms, independent t-test was utilized for ten subscales. Levene's test was also performed in order to assess the equality of variances between the two groups. Cohen's d was calculated as a measure of effect size in order to overcome the shortcomings of sample size and statistical significance tests. One-way analysis of variance was used to examine between-group differences across educational levels and marital status. Moreover, Pearson correlation coefficient was computed between age and total score of SCL-90-R. Data analytic procedures were performed by SPSS 18.

\section{Results}

First, a data screening procedure was conducted to correct possible flaws in the process of coding and to replace few missing data. Demographic details were also controlled for potential differences. Women and men did not differ significantly in age $(\mathrm{P}>0.05)$ and educational level $(\mathrm{P}>0.05)$.

Both groups were compared in ten different subscales. Findings of the independent t-tests are presented in Table 2. One-tailed p-values have been computed for statistical significance because of the nature of the study's hypothesis. Women showed stronger symptoms in 4 subscales; namely, anxiety, obsessive-compulsive symptoms, depression, and added items. Effect size ranged between 0.19 (phobia subscale) and 0.69 (anxiety subscale). It needs to be noted that mean score of females was higher in all subscales; however, the relationship was significant in four subscales.

One-way ANOVA detected no between-group difference between single, married, and separated individuals $(P>0.05)$. Moreover, bivariate correlation coefficients of age and subscales were not significant $(P>0.05)$. 
Table 2. Descriptive and inferential information of subscales.

\begin{tabular}{|c|c|c|c|c|c|c|}
\hline Variable & Group & Mean (SD) & t-test statistic & $\mathrm{df}$ & P-value & Effect size (d) \\
\hline \multirow{2}{*}{ Somatization } & Male & $7.10(5.35)$ & \multirow{2}{*}{0.961} & \multirow{2}{*}{49} & \multirow{2}{*}{0.170} & \multirow{2}{*}{0.28} \\
\hline & Female & $8.96(7.36)$ & & & & \\
\hline \multirow{2}{*}{ Anxiety } & Male & 3.47 (3.67) & \multirow{2}{*}{2.511} & \multirow{2}{*}{49} & \multirow{2}{*}{0.008} & \multirow{2}{*}{0.69} \\
\hline & Female & $6.96(5.35)$ & & & & \\
\hline \multirow{2}{*}{ Obsessive-compulsive } & Male & $7.47(5.92)$ & \multirow{2}{*}{1.704} & \multirow{2}{*}{49} & \multirow{2}{*}{0.048} & \multirow{2}{*}{0.48} \\
\hline & Female & $10.62(6.64)$ & & & & \\
\hline \multirow{2}{*}{ Depression } & Male & $6.89(7.11)$ & \multirow{2}{*}{1.832} & \multirow{2}{*}{49} & \multirow{2}{*}{0.037} & \multirow{2}{*}{0.52} \\
\hline & Female & $10.81(7.54)$ & & & & \\
\hline \multirow{2}{*}{$\begin{array}{c}\text { Interpersonal } \\
\text { sensitivity }\end{array}$} & Male & 6.63 (5.79) & \multirow{2}{*}{1.373} & \multirow{2}{*}{49} & \multirow{2}{*}{0.088} & \multirow{2}{*}{0.39} \\
\hline & Female & $9.06(6.29)$ & & & & \\
\hline \multirow{2}{*}{ Psychoticism } & Male & $5.63(4.69)$ & \multirow{2}{*}{0.499} & \multirow{2}{*}{49} & \multirow{2}{*}{0.310} & \multirow{2}{*}{0.15} \\
\hline & Female & $6.37(5.38)$ & & & & \\
\hline \multirow{2}{*}{ Paranoid ideation } & Male & $5.36(4.16)$ & \multirow{2}{*}{1.629} & \multirow{2}{*}{49} & \multirow{2}{*}{0.055} & \multirow{2}{*}{0.46} \\
\hline & Female & $7.40(4.40)$ & & & & \\
\hline Ho tilit & Male & $4.21(4.18)$ & דרים & 10 & > & 02 \\
\hline Позипाу & Female & $5.06(3.14)$ & $0.0<0$ & 49 & 0.207 & 0.24 \\
\hline Dholi. & Male & $3.26(3.71)$ & 0.643 & 10 & לר: & 010 \\
\hline Filovid & Female & $3.90(3.29)$ & & 49 & 0.202 & 0.19 \\
\hline old & Male & $5.15(3.56)$ & 1757 & 10 & 001 & $0-0$ \\
\hline Auded nents & Female & $7.28(4.49)$ & 1.703 & 49 & 0.043 & 0.00 \\
\hline
\end{tabular}

\section{Discussion}

This study aimed to compare different components of psychopathology between men and women in a sample of aesthetic rhinoplasty candidates. Results suggest that female patients fare worse in four subscales of SCL-90-R out of total ten subscales. Nevertheless, women had higher scores in all subscales. Effect size evaluation indicated a comparatively strong relationship in anxiety, obsessive-compulsive symptoms, depression, and paranoid ideation.

One possible explanation for above-mentioned findings is that female patients are more obsessed with their appearance and psychologically disturbed women seek rhinoplasty as a mean to achieve a better look. On the other hand, men may seem more realistic with their body and they are exposed to media to a lesser extent. Moreover, findings are consistent with the notion that positive body image is higher in men. Yet, Wright [24] reported that male patients brought a set of unexplored motivations and expectations to the surgeon along with unresolved emotional conflicts resulting in feelings of ambivalence, emotional instability, and sometimes even hostility toward the surgeon. The present study's findings are inconsistent with the notion that male aesthetic patients are more psychologically at-risk compared to the female aesthetic patients. While female aesthetic patients may benefit from aesthetic surgeries to a higher extent [25], male patients showed less preoperative symptoms of psychopathology in comparison with their female counterparts.

It has also been suggested that in general, men tend to have a poorer understanding of their deformity than do women. Thus, they cannot describe the changes they expect from the surgery [24] [26]. This tendency, combined with a tendency toward selective hearing among male patients, makes it even more important that the physician determine the patient's goals and establish whether they are realistic during the initial consultation. Perhaps, the expectations of aesthetic rhinoplasty in the male patients are higher or even more ambiguous compared to female patients; however, the preoperative exhibition of psychopathological symptoms is more severe among women who apply for aesthetic rhinoplasty.

Once more, it can be concluded that collaboration of facial plastic surgeons with psychologists/psychiatrists can play a crucial role in screening related disorders such as depression, anxiety disorders, Obsessive-Compu- 
lsive and Related Disorders (OCRD), etc. since rhinoplastic patients show higher scores of psychopathology in some specific domains, it is recommended for future research to develop a specific psychometric instrument in order for screening those specific disorders for this population.

Further research in the field of gender differences in cosmetic surgery may bring more confidence to the results of this study. One limitation of the current study was its sampling method as convenience sampling method runs the risk of acquiring limited results. Second limitation would be the administered instrument as SCL-90-R is limited to dimensions of psychopathology. Inclusion of other disorders such as Body Dysmorphic Disorder (BDD) could strengthen the results. Thus, it is highly recommended to investigate the gender differences in the field of cosmetic plastic surgery using various psychometric instruments and interviews.

\section{Conclusion}

Women who apply for aesthetic rhinoplasty score higher in anxiety, depression, obsessive-compulsive symptoms, and psychopathological symptoms compared to their male counterparts. Surgeons can use brief questionnaires to screen psychologically disturbed patients. This process seems more important in case of female patients.

\section{References}

[1] Rohrich, R.J. (2003) The American Society of Plastic Surgeons' Procedural Statistics: What They Really Mean. Plastic and Reconstructive Surgery, 112, 1389-1392. http://dx.doi.org/10.1097/01.PRS.0000084284.02024.3B

[2] Cash, T.F. and Pruzinsky, T.E. (1990) Body Images: Development, Deviance, and Change. Guilford Press, New York.

[3] Yild1z, T. and Selimen, D. (2014) The Impact of Facial Aesthetic and Reconstructive Surgeries on Patients' Quality of Life. Indian Journal of Surgery, 1-6. http://dx.doi.org/10.1007/s12262-013-1024-z

[4] Sarwer, D.B. and Crerand, C.E. (2004) Body Image and Cosmetic Medical Treatments. Body image, 1, 99-111. http://dx.doi.org/10.1016/S1740-1445(03)00003-2

[5] Langlois, J.H., Kalakanis, L., Rubenstein, A.J., Larson, A., Hallam, M., and Smoot, M. (2000) Maxims or Myths of Beauty? A Meta-Analytic and Theoretical Review. Psychological Bulletin, 126, 390-423. http://dx.doi.org/10.1037/0033-2909.126.3.390

[6] Aharon, I., Etcoff, N., Ariely, D., Chabris, C.F., O’Connor, E. and Breiter, H.C. (2001) Beautiful Faces Have Variable Reward Value: fMRI and Behavioral Evidence. Neuron, 32, 537-551. http://dx.doi.org/10.1016/S0896-6273(01)00491-3

[7] Rhodes, G., Simmons, L.W. and Peters, M. (2005) Attractiveness and Sexual Behavior: Does Attractiveness Enhance Mating Success? Evolution and Human Behavior, 26, 186-201. http://dx.doi.org/10.1016/j.evolhumbehav.2004.08.014

[8] Hosoda, M., Stone-Romero, E.F. and Coats, G. (2003) The Effects of Physical Attractiveness on Job-Related Outcomes: A Meta-Analysis of Experimental Studies. Personnel Psychology, 56, 431. http://dx.doi.org/10.1111/j.1744-6570.2003.tb00157.x

[9] Amodeo, C.A. (2007) The Central Role of the Nose in the Face and the Psyche: Review of the Nose and the Psyche. Aesthetic Plastic Surgery, 31, 406-410. http://dx.doi.org/10.1007/s00266-006-0241-2

[10] Babuccu, O., Latifoglu, O., Atabay, K., Oral, N. and Cosan, B. (2003) Sociological Aspects of Rhinoplasty. Aesthetic Plastic Surgery, 27, 44-49. http://dx.doi.org/10.1007/s00266-002-1517-9

[11] Naraghi, M. and Atari, M. (2015) Comparison of Patterns of Psychopathology in Aesthetic Rhinoplasty Patients versus Functional Rhinoplasty Patients. Otolaryngology—Head and Neck Surgery, 152, 244-249. http://dx.doi.org/10.1177/0194599814560139

[12] Di Mattei, V.E., Bagliacca, E.P., Lavezzari, L., Di Pierro, R., Carnelli, L., Zucchi, P., Bruffaldi Preis, F. and Sarno, L. (2015) Body Image and Personality in Aesthetic Plastic Surgery: A Case-Control Study. Open Journal of Medical Psychology, 4, 35. http://dx.doi.org/10.4236/ojmp.2015.42004

[13] Naraghi, M. and Atari, M. (2015) A Comparison of Depression Scores between Aesthetic and Functional Rhinoplasty Patients. Asian Journal of Psychiatry, 14, 28-30. http://dx.doi.org/10.1016/j.ajp.2015.01.009

[14] Javanbakht, M., Nazari, A., Javanbakht, A. and Moghaddam, L. (2012) Body Dysmorphic Factors and Mental Health Problems in People Seeking Rhinoplastic Surgery. Acta Otorhinolaryngologica Italica, 32, 37-40.

[15] Naraghi, M. and Atari, M. (2014) Comparison of Self-Esteem Status in Aesthetic and Functional Rhinoplasty Patients. Otolaryngology—Head and Neck Surgery, 151, 139. http://dx.doi.org/10.1177/0194599814541629a7

[16] Pecorari, G., Gramaglia, C., Garzaro, M., Abbate-Daga, G., Cavallo, G.P., Giordano, C. and Fassino, S. (2010) 
Self-Esteem and Personality in Subjects with and without Body Dysmorphic Disorder Traits Undergoing Cosmetic Rhinoplasty: Preliminary Data. Journal of Plastic, Reconstructive \& Aesthetic Surgery, 63, 493-498. http://dx.doi.org/10.1016/j.bjps.2008.11.070

[17] Atari, M., Akbari-Zardkhaneh, S., Mohammadi, L. and Soufiabadi, M. (2015) The Factor Structure and Psychometric Properties of the Persian Version of Body Appreciation Scale. American Journal of Applied Psychology, 3, 62-66.

[18] Atari, M., Akbari-Zardkhaneh, S., Soufiabadi, M. and Mohammadi, L. (2015) Cross-Cultural Adaptation of the Physical Appearance Comparison Scale-Revised in Iran. International Journal of Body, Mind and Culture, 2, 1-10.

[19] Picavet, V.A., Prokopakis, E.P., Gabriëls, L., Jorissen, M. and Hellings, P.W. (2011) High Prevalence of Body Dysmorphic Disorder Symptoms in Patients Seeking Rhinoplasty. Plastic and Reconstructive Surgery, 128, 509-517. http://dx.doi.org/10.1097/PRS.0b013e31821b631f

[20] Henderson-King, D. and Henderson-King, E. (2005) Acceptance of Cosmetic Surgery: Scale Development and Validation. Body Image, 2, 137-149. http://dx.doi.org/10.1016/j.bodyim.2005.03.003

[21] Tylka, T.L. (2013) Evidence for the Body Appreciation Scale’s Measurement Equivalence/Invariance between US College Women and Men. Body Image, 10, 415-418. http://dx.doi.org/10.1016/j.bodyim.2013.02.006

[22] Brown, A., Furnham, A., Glanville, L. and Swami, V. (2007) Factors That Affect the Likelihood of Undergoing Cosmetic Surgery. Aesthetic Surgery Journal, 27, 501-508. http://dx.doi.org/10.1016/j.asj.2007.06.004

[23] Derogatis, L.R., Rickels, K. and Rock, A.F. (1976) The SCL-90 and the MMPI: A Step in the Validation of a New Self-Report Scale. The British Journal of Psychiatry, 128, 280-289. http://dx.doi.org/10.1192/bjp.128.3.280

[24] Wright, M.R. (1987) The Male Aesthetic Patient. Archives of Otolaryngology-Head \& Neck Surgery, 113, $724-727$. http://dx.doi.org/10.1001/archotol.1987.01860070038012

[25] Ercolani, M., Baldaro, B., Rossi, N., Trombini, E. and Trombini, G. (1999) Short-Term Outcome of Rhinoplasty for Medical or Cosmetic Indication. Journal of Psychosomatic Research, 47, 277-281. http://dx.doi.org/10.1016/S0022-3999(99)00042-2

[26] Rohrich, R.J., Janis, J.E. and Kenkel, J.M. (2003) Male Rhinoplasty. Plastic and Reconstructive Surgery, 112, 1071-1086. http://dx.doi.org/10.1097/01.PRS.0000076201.75278.BB 